\title{
Les Systèmes de communication Approche socio- anthropologique de Jean Lohisse, Paris, Armand Colin, 1998, 191 pages
}

\section{Patrick Baudry}

\section{QpenEdition}

\section{Journals}

Édition électronique

URL : http://journals.openedition.org/communicationorganisation/2063

DOI : 10.4000/communicationorganisation.2063

ISSN : 1775-3546

Éditeur

Presses universitaires de Bordeaux

Édition imprimée

Date de publication : 1 mai 1998

ISSN : 1168-5549

\section{Référence électronique}

Patrick Baudry, "Les Systèmes de communication Approche socio-anthropologique de Jean Lohisse,

Paris, Armand Colin, 1998, 191 pages », Communication et organisation [En ligne], 13| 1998, mis en ligne le 26 mars 2012, consulté le 20 avril 2019. URL : http://journals.openedition.org/ communicationorganisation/2063; DOI : 10.4000/communicationorganisation.2063

Ce document a été généré automatiquement le 20 avril 2019

(C) Presses universitaires de Bordeaux 


\title{
Les Systèmes de communication Approche socio-anthropologique de Jean Lohisse, Paris, Armand Colin, 1998, 191 pages
}

\author{
Patrick Baudry
}

1 En pays étranger nous voyons des gens se parler, se faire des signes, porter des papiers, prendre des attitudes. Ils communiquent, c'est-à-dire qu'il se comprennent, et l'on peut s'étonner de ces « charabias » verbaux, gestuels ou paperassiers dont l'organisation nous échappe. Sans doute pourrait-on décrire à l'infini ces manières « exotiques » de dire et de faire savoir par quoi les membres de sociétés différentes se disent quelque chose. Mais notre étonnement devant des coutumes étrangères et surtout devant leur efficacité comment donc parviennent-ils à se comprendre vraiment? - est bien à la mesure de l'oubli que nous pratiquons des codes sociaux qui régissent nos propres échanges.

2 Gestes ordinaires mais ritualisés, phrases coutumières mais mises en scènes, logique d'honneur de la parole donnée, autorité de l'écrit, toutes les interactions communicationnelles (gestuelles, parolières ou scripturaires) participent de systèmes qu'elles véhiculent et contribuent à reproduire. Au-delà de la seule description des séquences d'interactions (et en opérant un retour sur nos propres cultures occidentales comme nous y invite l'anthropologie d'aujourd'hui), il faut accéder à l'analyse de ces systèmes de communication. Pour cela, il faut en proposer une théorisation dynamique. Telle est l'intention de Jean Lohisse.

3 Il ne faut pas seulement référer ce qui se dit au contexte d'énonciation comme s'il suffisait de relier l'intériorité d'une interaction à une extériorité sociale, c'est-à-dire comme si la société n'était qu'un environnement général et vague ou une sorte de décor aux influences mal évaluables. Il faut comprendre comment ce que l'on voudrait désigner comme le "dehors » d'un échange contribue en fait activement à sa fabrication en traitant dans leurs relations complexes et évolutives des langages, des mentalités 
collectives et des structures sociétales. La phrase, la mimique, le geste ou la posture communiquent la société qui les construit. Parler - parler tout «simplement» - c'est parler la pensée d'une société, tout en même temps que cette pensée s'élabore dans cette parole même ou dans cette gestualité aux apparences immédiates. Des médiations, c'està-dire des logiques qui les organisent, sont à l'œuvre : lesquelles ?, et pour la production de quel monde?

4 Analyser des dispositifs de communication et en souligner les enjeux, tel est l'objectif majeur du livre vivant et érudit de Jean Lohisse. En usant de typologies au moyen desquelles il privilégie ainsi la macro-analyse, l'auteur se garde bien de généraliser ou de catégoriser : il situe des formes socio-communicationnelles en en saisissant la structure de sens. Quatre genres caractéristiques sont distinguées: l'oralité, la scribalité, la massalité et l'informalité. Ajuste titre, l'auteur attire notre attention sur l'illusion que nous pourrions avoir de penser bien connaitre le sens des deux premiers termes sous ce prétexte qu'on les emploie plus aisément, tandis que les deux derniers devraient sembler plus obscurs. Sait-on vraiment ce que signifie une culture de l'oralité et quelles en sont les logiques de communication? A-t-on bien mesuré l'importance de l'écrit et de ses impacts? Quant aux nouveautés typiques d'une modernité récente ou actuelle, sait-on les situer dans une perspective historique et en dégager réellement les enjeux ? La société de masse génère une forme communicationnelle nouvelle. Et la place que prend l'information comme énergie et non seulement comme contenu, modifie encore les données. Innovation technologique, échanges interculturels, remaniement du socle politique, modification du rapport au monde..., sont autant d'occasions de changements plus ou moins potentialisés et dont il n'est jamais aisé de prévoir tous les effets. Jean Lohisse oblige à penser la complexité des cultures communicationnelles et leurs dynamismes. Il nous donne à comprendre pourquoi à l'oralité correspond la communion, à la scribalité le partage, à la massalité la diffusion et à l'informalité la commutation. Ce que l'on comprend aussi bien c'est que le sens même du mot «communication» se modifie chaque fois...

Publié dans l'excellente collection Cursus, ce livre tient tout à la fois de la synthèse utile aux étudiants et de l'ouvrage de fond. De l'outil de travail et du beau livre. 